\title{
PERMANÊNCIA E EVASÃO ESCOLAR: UM ESTUDO DE CASO EM UMA INSTITUIÇÃO DE ENSINO PROFISSIONAL
}

\author{
J. A. SILVEIRA SOUZA \\ Instituto Federal de Educação, Ciência e Tecnologia do Ceará \\ juarina.silveira@ifce.edu.br
}

Artigo submetido em outubro/2013 e aceito em dezembro/2013

DOI: $10.15628 /$ rbept.2013.3498

\section{RESUMO}

A presente pesquisa tem como objetivo analisar o fenômeno da permanência e evasão escolar nos cursos oferecidos na Educação Profissional de Nível Técnico, com ênfase no Curso Técnico Subsequente de Redes de Computadores, ofertado pelo Instituto Federal de Educação, Ciência e Tecnologia do Rio Grande do Norte IFRN, Campus São Gonçalo do Amarante. Busca-se com isso contribuir com reflexões e proposição de uma política para a diminuição da evasão escolar tão frequente nos cursos técnicos subsequentes. Os instrumentos utilizados consistiram em análise documental, aplicação de questionário e entrevista semiestruturada, os quais permitiram a coleta de dados e análise qualitativa. Os resultados mostraram que os fatores relacionados à permanência ou à evasão escolar estão intrinsecamente relacionados aos aspectos internos à instituição, corroborando com o aporte teórico utilizado. Fatores como: o perfil/desempenho do corpo discente, os recursos e estruturas físicas escolares, os processos e as práticas pedagógicas foram citados como importantes para favorecer a permanência do aluno.

PALAVRAS-CHAVE: permanência e evasão escolar; educação profissional; escola técnica de nível médio.

\section{STAYING AND EVASION SCHOOL: A CASE STUDY IN A PROFESSIONAL EDUCATIONAL INSTITUTION}

\begin{abstract}
This research aims to analyze the permanence phenomenon and truancy in courses offered in Technical Professional Education, with an emphasis on course Subsequent Technician Computer Networks, offered by the Federal Institute of Education, Science and Rio Grande do Norte Technology - IFRN, Campus São Gonçalo do Amarante. It seeks to contribute to this reflection and propose a policy to reduce truancy so often in subsequent technical courses. The instruments used consisted of documentary analysis, a questionnaire and
\end{abstract}

semi-structured interview, which allowed data collection and qualitative analysis. The results showed that the factors related to permanence or truancy are intrinsically related to the internal aspects of the institution, confirming the theoretical approach. Factors such as the profile/student body performance, resources and school physical structures, processes and pedagogical practices were cited as important to favor the permanence of the student.

KEYWORDS: permanence and truancy; professional education; mid-level technical school. 


\section{INTRODUÇÃO}

O presente artigo é resultado de uma investigação de dissertação de Mestrado já concluída em 2014, que analisou os motivos que levam os alunos a permanecerem ou evadirem dos cursos oferecidos na Educação Profissional de Nível Técnico, com ênfase no Curso Técnico Subsequente de Redes de Computadores, ofertado pelo Instituto Federal de Educação, Ciência e Tecnologia do Rio Grande do Norte - IFRN, Campus São Gonçalo do Amarante, com o intuito de contribuir com reflexões e proposição de uma política para o enfrentamento dessa questão na realidade escolar.

Assim sendo, faz-se necessário investigar o que se passa no seio da escola técnica profissional que, por seu know-how social e pela exigência do mercado de trabalho por profissionais qualificados, continua atraindo muitos jovens, mas, ao mesmo tempo, vive um dilema por não estar conseguindo fazer com que os que nela ingressam, permaneçam até a conclusão do curso.

E o que é preciso para tornar estas escolas mais atraentes para os jovens? Quais fatores favorecem a permanência do aluno no curso escolhido? E quais fatores dificultam sua permanência, levando à evasão escolar? É a busca por respostas para estas interrogações que motivou este estudo, na perspectiva de que as possíveis respostas encontradas possam contribuir para a discussão desse fenômeno nas instituições de Educação Profissional, em especial, no Instituto Federal de Educação, Ciência e Tecnologia do Rio Grande do Norte, campus São Gonçalo do Amarante, principal lócus desta pesquisa.

Com a finalidade de se obter respostas para as indagações acima, a presente investigação tem como objetivo geral investigar os fatores que contribuem para a permanência escolar no Curso de Redes de Computadores, do IFRN, Campus SGA; e como objetivos específicos: Analisar as percepções dos diferentes atores sobre o fenômeno investigado, bem como propor uma intervenção pedagógica como estratégia de enfrentamento desta problemática.

Foi realizada uma pesquisa essencialmente qualitativa, por se tratar da análise de um fenômeno social por meio de um estudo de caso. Como instrumentos de coletas de dados, foram utilizados: pesquisa bibliográfica, pesquisa documental, entrevista e questionário.

Neste sentido, esse trabalho encontra-se estruturado da seguinte forma: inicialmente, apresenta a trajetória histórica da Instituição IFRN, procurando contextualizar e caracterizar o curso ofertado, para enriquecer a compreensão do caso.

Num segundo momento, discute a questão dos fatores que estão relacionados com a permanência ou evasão escolar na Educação Básica e no Ensino Técnico Profissional à luz do aporte teórico.

Em seguida, analisa e interpreta os dados sobre o olhar da escola à luz do referencial teórico; e finalmente, tece algumas considerações finais, e propõe uma intervenção pedagógica de enfrentamento da problemática. 


\section{DE ESCOLA DE APRENDIZES DE ARTÍFICES A INSTITUTO FEDERAL DE EDUCAÇÃO, CIÊNCIA E TECNOLOGIA}

Os Institutos Federais de Educação surgem num período histórico determinado e com objetivos claros, sendo preciso compreendê-lo no âmbito das políticas educacionais do Brasil.

Essas Instituições de Ensino Profissional, ao longo de seus mais de cem anos, sofreram diversas transformações tanto de denominações quanto de concepções ideológico - educacionais. De Escola de Aprendizes de Artífices, em 1909, quando foi criada, a Instituto Federal de Educação, Ciência e Tecnologia em 2008, com a promulgação da Lei no 11.892, a mais recente mudança na rede federal de educação, transformando os CEFET'S - Centros Federais de Educação Tecnológica em Institutos Federais, iniciando, paralelamente, um processo de expansão e interiorização da Rede Federal de Educação.

O modelo atual dessas instituições compete entre si e com as universidades, pelos alunos e pelo prestígio social que conseguiu ao longo de sua história de sucesso educacional, conquistado pelos indicadores educacionais, de empregabilidade, de produção científica, de internacionalização, etc.

O Instituto Federal de Educação, Ciência e Tecnologia do Rio Grande do Norte (IFRN), nos últimos anos, acompanhou esta política nacional de expansão, obtendo um crescimento significativo da sua rede no Estado, como também, ampliou seus horizontes de atuação, com a oferta, inclusive, de cursos de pós-graduação lato sensu e, mais recentemente, strictu sensu.

Todavia, esse crescimento em um pequeno intervalo de tempo, tem despertado preocupações à comunidade acadêmica quanto à qualidade de seu desempenho nessa nova fase de sua história. Uma dessas inquietações é a evasão escolar que vem crescendo na instituição, em especial em alguns cursos e modalidades.

São desafios que permeiam por todos os campi. E no campus São Gonçalo do Amarante SGA, também não é diferente. Nesse sentido, passaremos, agora, a conhecer um pouco do campus para adentrarmos, posteriormente, na problemática da evasão escolar que está ocorrendo no curso de Redes de computadores, foco da nossa pesquisa.

O Campus SGA fica situado na região metropolitana de Natal. A oferta de seus cursos foi projetada de acordo com os eixos tecnológicos: o de Infraestrutura, que conta com o curso técnico Edificação, na forma Integrada e Subsequente, e o eixo de Gestão e Negócios, com o técnico de nível médio e superior em Logística para atender os arranjos produtivos da região na qual está inserido.

O Curso de Redes de Computadores faz parte do eixo Informação e Comunicação; um eixo transversal presente em todas as unidades do IFRN, por sua importância no mundo contemporâneo, dado à relevância que se dá a tecnologia da informação e comunicação no cenário mundial.

Para compreendermos quais fatores influenciam na permanência escolar no curso de Redes de Computadores, faz-se necessário uma análise, mesmo que de forma resumida, dos seus indicadores educacionais, que foram coletados junto à Secretaria Acadêmica do campus, os quais se referem ao número de alunos que se matricularam no segundo semestre de 2011 , bem como a situação da turma ao final do último período. 
Embora essa pesquisa tenha como foco a permanência escolar, não se pode desconsiderar a existência de evasão escolar no curso em estudo, no intuito de se entender os motivos que fazem com que uns permaneçam e outros abandonem de vez a escola; assim, justifica-se que seja feita uma menção quanto à evasão escolar1.

Os dados apontam uma matrícula inicial de 71 alunos no semestre 2011.1, distribuídos em duas turmas. A seguir, na tabela 1, apresentaremos o rendimento das turmas ao final dos quatro semestres cursados.

Tabela 1: Situação final dos alunos ingressante em $\mathbf{2 0 1 1 . 2}$

\begin{tabular}{ll}
\hline Concluintes & $12(17 \%)$ \\
\hline Evadidos & $31(43,6 \%)$ \\
Cancelamento compulsório & $06(8,45 \%)$ \\
Cancelado & $12(17 \%)$ \\
Trancado & $02(2,81)$ \\
Em outros períodos & $05(7,0 \%)$ \\
Dependência & $02(2,8 \%)$ \\
Reprovado & $01(1,4 \%)$ \\
Total & 71 \\
\hline
\end{tabular}

Fonte: IFRN/Campus SGA/2013

Analisando a situação final das turmas ingressantes em 2011.2, observamos um grande filtro, apenas $17 \%$ concluíram o curso no tempo regular; cerca de $11 \%$ somam os alunos que ainda continuam no curso e que faltam integralizar algumas disciplinas, estando em períodos diversos; $2,8 \%$ fizeram trancamento, podendo retornar dentro do prazo limite de conclusão; 25,5\% representa o percentual de cancelamento e $43,6 \%$ de evadidos. Ocorreu, portanto, uma alta taxa de evasão nessas turmas, fato que precisa ser investigado para entender que fatores contribuíram para a desistência de tantos alunos.

Para compreendermos melhor as causas que levaram os alunos a saírem do curso, coletamos ainda, outros dados relativos às razões pelas quais houve o Cancelamento Voluntário de Matrícula de 15,5\% dos alunos, conforme a tabela $\mathrm{n} \cong 2$.

Tabela 2: Motivos de cancelamento voluntário de matrícula

\begin{tabular}{lc}
\hline \multicolumn{1}{c|}{ Motivos do cancelamento } & Quant. Alunos \\
\hline Incompatibilidade de horário com o trabalho. & 02 \\
Aprovado em outro curso, em outra instituição. & 04 \\
Mudança de curso no mesmo campus. & 04 \\
Motivos de força maior. & 01 \\
\hline
\end{tabular}

Fonte: IFRN/Campus SGA/2012.

Esses dados não são considerados como evasão escolar pelo sistema acadêmico, mas o fato é que estes alunos não permaneceram no curso. Em suma, para a nossa análise, interessa-nos a reflexão sobre a situação das turmas 2011.2, uma vez que apenas $28 \%$ dos alunos permaneceram na escola e destes apenas $17 \%$ concluíram regularmente. Como explicar tal situação? Olhar como algo natural dos cursos subsequentes? Ou a escola tem a responsabilidade de mudar ou minimizar esta realidade para que mais alunos consigam permanecer até a conclusão do curso?

\footnotetext{
${ }^{1}$ Segundo o INEP (Instituto Nacional de Estudos e Pesquisas Educacionais Anísio Teixeira), há uma diferença conceitual entre evasão e abandono escolar. "Abandono quer dizer que o aluno deixa a escola num ano, mas retorna no ano seguinte. Evasão significa que o aluno sai da escola e não volta mais para o sistema" (INEP, 2014).
} 
Quando analisamos a trajetória ao longo dos períodos, percebemos que as turmas vão diminuindo, como se existisse um funil. Será que poderíamos falar como Santos e Pouchain (s/d) em 'seleção dos melhores'? Só os melhores permanecem? Parece existir, pois,

\begin{abstract}
Uma finalidade expressa do sistema educacional, a formação de todos os alunos, e uma finalidade inconfessa, a seleção dos melhores. Talvez não seja de todo correto falar da "seleção dos melhores" e se devesse dizer "a exclusão dos piores". O sistema educacional vai estabelecendo uma série de filtros ao longo de suas diferentes etapas que vão deixando de fora os menos capazes. Os demais alunos, entre os quais estão os melhores, os bons, os regulares, alguns fracos, e inclusive outros com escassos conhecimentos, continuam no nível seguinte de estudos. (SANTOS; POUCHAIN, s/d, p. 307).
\end{abstract}

A função social da instituição é pautada numa perspectiva de educação de qualidade, democrática e cidadã, preceitos, estes, que devem ser garantidos a todos, e não apenas a uma parcela. São reflexões que a instituição precisa fazer e buscar alternativas de amenizar tal problemática.

\title{
3 FATORES DE PERMANÊNCIA E DE EVASÃO ESCOLAR NO UNIVERSO DA EDUCAÇÃO BÁSICA E NO ENSINO TÉCNICO PROFISSIONAL
}

Várias são as pesquisas que têm investigado a permanência e a evasão escolar na tentativa de compreender que fatores estão associados ao fenômeno, no intuito, inclusive, de se pensar em intervenções pedagógicas e em políticas educacionais para sanar tal deficiência na escola brasileira. É importante ressaltar que não são tantos estudos assim; encontram-se muito poucos sobre a temática, em especial quando se restringe à escola de ensino técnico profissional.

Pela revisão da literatura nacional e internacional, este fenômeno não se restringe à educação do Brasil, muito embora, a situação brasileira seja bem mais alarmante. No Brasil, ainda, concentra altos índices de evasão, indo na contramão do que prega a Lei de Diretrizes e Bases da Educação, Lei no 9394/96, que tem como um de seus princípios "igualdade de condições de acesso e permanência escolar", em seu Art. 3ㅇ (Brasil, 1996.) Porém, mesmo o aluno tendo acesso à escola, não representa garantia de sucesso escolar, muitos não permanecem nos bancos escolares; a garantia da permanência escolar ainda se configura como um gargalo na educação brasileira.

Apesar de algumas políticas educacionais terem sido implementadas pelos Estados e Ministério da Educação para o Ensino Médio, principalmente nas duas últimas décadas, o país não tem atingido o retorno necessário na redução dessas taxas. Além disso, a universalização do ensino na escola média ainda representa um desafio ao país, uma vez que milhares de jovens na faixa de idade de 15 a 17 anos ainda não estão nos bancos escolares, representando uma grande dívida da sociedade com esta parcela da população brasileira.

A taxa de atendimento nessa faixa etária, em 2010 , era de $83,3 \%$, sendo que desse total apenas $47,3 \%$ deles correspondem à taxa de escolaridade líquida, definida como sendo a proporção de jovens que se encontram na faixa etária adequada nesse nível educacional. (IBGE, 2010) 
Vale ressaltar que o novo Plano Nacional de Educação (PNE) 2011 - 2020 tem como meta universalizar o Ensino Médio entre 15 a 17 anos até 2016. Outra meta do PNE é alcançar 85\% de taxa de escolarização líquida na faixa etária de 15 a 17 anos de idade no Ensino Médio em 2020.

Em se tratando de Educação Técnica Profissional, o novo Plano Nacional de Educação para 2011-2020 (PNE, 2011) prevê ampliar gradualmente suas taxas de conclusão para 90\%; mas ainda se tem um longo caminho a percorrer diante da atual realidade da escola técnica profissional nesse quesito.

Os estudos de Dore Soares e Lüscher (2011) enfatizam que muitas são as situações que estão associadas ao fenômeno da evasão escolar. Devem-se levar em conta situações diversas quanto à retenção do aluno na escola, a saída do aluno da instituição, a saída do aluno do sistema de ensino, a não conclusão de um determinado nível de ensino, a evasão da escola e posterior retorno. Pode-se também referir, ainda, segundo as autoras, àqueles indivíduos que nunca ingressaram em um determinado nível de ensino, especialmente na educação compulsória, bem como ao estudante que concluiu um determinado nível de ensino, mas se comporta como um desistente. As autoras ainda chamam a atenção para outro aspecto que consideram relevantes nas situações de evasão: o nível escolar em que ela ocorre, uma vez que a evasão difere significativamente nos diferentes níveis e modalidades educacionais.

Outro aspecto complexo na compreensão do fenômeno é quanto suas possíveis causas. Pelas pesquisas já realizadas sobre o assunto, percebe-se que a evasão é consequência de um conjunto de fatores que se relacionam tanto ao estudante e à sua família quanto à escola e à comunidade em que vive, como veremos a seguir.

As autoras se apoiaram nas pesquisas de Rumberger (2004), que identificou duas principais perspectivas como contextos de investigação do problema: a individual, que envolve o estudante e as circunstâncias de sua trajetória escolar, e a institucional, que leva em consideração a família, a escola, a comunidade e os grupos de amigos. No aspecto individual, consideram-se os valores, os comportamentos e as atitudes que favorece um maior ou menor engajamento do estudante na vida escolar.

Conforme essas pesquisas há dois tipos de engajamento: o engajamento acadêmico/aprendizagem e o engajamento social/convivência do estudante com os colegas, com os professores e com os demais sujeitos da comunidade escolar. "A forma como o estudante se relaciona com essas duas dimensões da vida escolar interfere de modo decisivo sobre sua deliberação de se evadir ou de permanecer na escola" (RUMBERGER (2004) apud DORE SOARES E LÜSCHER, 2011, p.05).

Quanto à perspectiva da escola, as autoras citam que, dentre, os fatores que podem ser relacionados à saída/evasão ou à permanência do estudante na escola, relaciona-se com: o perfil do corpo discente, os recursos e estruturas físicas escolares, os processos e as práticas pedagógicas. E por fim, essas pesquisas apontam que a comunidade e os grupos de amigos também têm grande influência sobre os processos de evasão ou permanência escolar.

Do vasto e intricado conjunto de circunstâncias individuais, institucionais e sociais presentes na análise da evasão, destaca-se a explicação de que a evasão é um processo complexo, dinâmico e cumulativo de desengajamento do estudante da 
vida da escola. A saída do estudante da escola é apenas o estágio final desse processo. (DORE SOARES E LÜCHER, 2011, p. 06).

Quanto aos múltiplos fatores de evasão escolar na educação profissional de nível técnico, Luscher e Dore (2011) sinalizam para a existência de oportunidades de escolhas e de experimentação profissional - mobilidade- por um lado, mas pode também representar a instabilidade e/ou falta de orientação do jovem quanto à carreira profissional que queira seguir. Pode indicar ainda, que está em curso um movimento que o estudante pode abandonar definitivamente o sistema.

Enfim, no caso da educação técnica de nível médio no Brasil, os aspectos relacionados à permanência ou à evasão escolar podem ser caracterizados sob várias perspectivas, o que torna muito difícil de compreender o fenômeno, seja no aspecto quantitativo ou qualitativamente. Uma vez que,

entre os percursos de formação profissional disponíveis no nível médio, o estudante pode, por exemplo, escolher um curso em uma determinada área, interrompê-lo e mudar de curso, mas permanecer na mesma área ou no mesmo eixo tecnológico. Pode também mudar de curso e de área/eixo ou, ainda, permanecer no mesmo curso e mudar apenas a modalidade do curso (integrado, subsequente ou concomitante) e/ou a rede de ensino na qual estuda. Outra opção é a de interromper o curso técnico para ingressar no Ensino Superior e, até mesmo, abandonar definitivamente qualquer proposta de formação profissional no nível médio. (LUSCHER; DORE, 2011, p. 152-3).

Para as autoras, a complexidade desse fenômeno demanda soluções também complexas, de difícil realização e que é necessário o envolvimento de diferentes agentes sociais. Os estudos sobre o assunto destacam a importância da prevenção e identificação precoce do problema e o acompanhamento individual dos possíveis estudantes que estão em situação de risco de evasão.

As autoras enfatizam, ainda, que em se tratando de educação técnica profissional, a evasão é um dos fatores mais significativo para "a baixa qualificação e habilitação profissionais apresentadas pelos jovens nas suas tentativas de ingresso no mercado de trabalho" (op. cit. p.153).

Porém, em virtude da diversidade de situações e causas que podem estar atreladas à evasão escolar, bem como as imprecisões conceituais, os pesquisadores concluem que ainda há uma grande defasagem de conhecimentos e informações a respeito do tema e que os problemas conceituais nessa área ainda não foram totalmente solucionados (LUSCHER; DORE, 2011).

Depreende-se, portanto, que a evasão apresenta uma série de fatores que precisam ser considerados, uma vez que consiste no desestímulo aos estudos por parte do aluno e esse desengajamento pode ser analisado da perspectiva do aluno, da escola e da sociedade, como já destacado neste trabalho, pelos estudos de Rumberger (op. cit.). Dessa forma, compreender a evasão envolve um estudo complexo de todas essas perspectivas.

\section{O OLHAR DA ESCOLA SOBRE O FENÔMENO}

Com a intenção de se compreender as causas que levaram às altas taxas de evasão no Curso Subsequente de Redes de Computadores no campus SGA, fomos buscar respostas junto ao grupo de alunos, gestores e docentes tanto do referido campus, como do de Parnamirim, outro campus 
do IFRN que também oferta o mesmo curso e poderia fornecer pistas de como esta comunidade escolar percebe o fenômeno e como vem enfrentando-lhe no seu cotidiano.

Debruçar-se no universo de cada sujeito participante, possibilitou-nos uma compreensão mais clara e abrangente dos prováveis motivos que favoreceram a evasão no curso de Redes de Computadores.

Constatou-se que a maioria dos alunos do Curso Subsequente de Redes de Computadores nos dois campi escolheu o curso aleatoriamente, sem conhecimento prévio sobre sua natureza; dos sete alunos entrevistados, apenas um em cada campus optou pelo curso conscientemente, por já atuar na área de tecnologia da informação; os demais escolheram aleatoriamente, pois era a única opção de curso, na época da seleção, e queriam ingressar numa escola de prestígio social.

[...] Na verdade, eu nem sabia o que era que eu iria estudar no Curso de Redes e nem estava nos meus planos fazer o Curso de Redes. O meu irmão é quem me falou e que ia abrir as turmas de Redes aqui no IF... aí me chamou pra fazer o Curso. Eu disse: Redes eu não quero [...] eu não sei nada da área. Mesmo assim, ele me inscreveu [...] E eu acredito que muita gente entrou no curso do mesmo jeito que eu. (Aluno 1, campus SGA, Informação verbal).

Essa constatação converge com as percepções dos gestores e professores de que o principal motivo de evasão no Curso Subsequente de Redes de Computadores nos dois campi é a falta de conhecimento sobre a natureza desse curso e, consequentemente, a falta de identificação com o mesmo, em virtude de suas peculiaridades.

[...] o pessoal que veio pra fazer Redes, não sabia exatamente o que é que o curso é... Qual era a proposta do curso pra que eles fizessem esse curso. Eles entraram, acredito, que desinformados. Eu acho que ainda continua da mesma forma, continua entrando desinformado [...] (PAT, campus SGA, Informação Verbal).

Além desse fator, outros aspectos são pontuados por gestores e professores como fatores de obstáculos para a permanência do aluno no referido curso, convergindo com a concepção dos diferentes autores utilizados para embasar este estudo, quando afirmam que a desistência do aluno se dá por uma multiplicidade de fatores.

Sobre esses empecilhos para permanência no curso, os principais fatores destacados pelos alunos foram quanto ao currículo, disciplinas consideradas de difícil compreensão e em relação à metodologia dos professores.

Muitas disciplinas, assim... Em algumas disciplinas o professor exigia muito do aluno, algumas até, eu considero alguns trabalhados que favoreciam mais aquelas pessoas que sabiam, já tinham um conhecimento prévio. [...] (Aluno 1, campus SAG, Informação Verbal).

Também neste estudo, identificamos que alguns aspectos institucionais obstaculizam a permanência discente, havendo inclusive, uma consonância entre a percepção dos alunos (fragmento verbal acima), dos gestores e dos professores sobre essas dificuldades institucionais.

A justificativa do grupo de gestores e professores, confirmada pelas falas dos alunos nos fragmentos acima, apoia-se na compreensão da baixa qualidade do Ensino Médio, em especial por serem alunos oriundos de escolas públicas. 
[...] aí tem também o fato daquele aluno, ele já vir com deficiências [...] porque também comparando o curso subsequente e o curso do integrado, é diferente por quê?... Vai consolidar esse conhecimento, então ele acaba desenvolvendo. Já o do subsequente, o perfil é diferente, [...] aí muitas vezes não tem tempo até mesmo pra se dedicar [...]. (G2, campus SGA, Informação Verbal).

A posição desses profissionais evidencia aquilo que Ribeiro (1991) chama atenção para o fato de que o fracasso escolar é quase sempre responsabilidade do aluno, nunca do professor ou da escola.

E nesse ponto pudemos constatar que para os discentes o fazer docente é visto como algo que influencia positivo ou negativamente para a permanência do aluno, evidenciado nos estudos de Dore Soares e Lücher ( 2011).

A metodologia do professor na época também... A maioria da turma não conseguia entender direito, isso foi no segundo semestre, né... A maioria não conseguia entender, acho que metade da turma "ficou" nessa disciplina, ou mais da metade. Porque realmente é uma disciplina muito, muito difícil. Tem que estudar muito... E a metodologia do professor realmente não ajudava. (Aluno 1, campus SGA, Informação Verbal).

Essa questão da prática do professor não foi somente enfatizada pela maioria dos alunos, como também pelas falas de $50 \%$ dos entrevistados do grupo de gestores e professores; de certa forma um percentual razoável, dada a razão de estarmos numa instituição de educação técnica profissional, quando a maioria dos docentes e gestores não é da área educacional.

[...] alguns reclamaram da metodologia de alguns professores a forma como estava sendo ofertada a disciplina, mas eles criticavam principalmente a metodologia de ensino, dificultava a aprendizagem e deixava o curso menos interessante pra eles (....) (PAP, campus SGA, Informação Verbal).

Constatou-se, ainda, quanto essa questão da prática do professor, uma troca de culpabilização entre alunos e docentes. O professor reclama que o aluno não estuda, o aluno reclama que o professor não busca formas de motivá-lo a estudar.

[...] É. Mas, há um incentivo? A grande questão é essa. Há um incentivo pra que o aluno estude? Há essa facilitação?. Então não havia algo que motivasse, né, com que essa turma estudasse, né?(Aluno 3, campus SGA, Informação Verbal).

Quanto aos aspectos que necessitam de aprimoramento institucional para o enfrentamento dessa problemática, constatamos que há certa consonância entre a visão dos alunos com a dos docentes e gestores, e que permeiam por questões referentes à prática docente, identificação com o curso, desempenho do aluno e integração de setores como pedagogia, psicologia e serviço social, como veremos abaixo nos depoimentos:

[...] Eu acho que poderia ter assim, um treinamento, uma capacitação pra esses professores pra ajudar eles mesmos a perceber tem pessoas diferentes, nem todo mundo pensa do mesmo jeito, nem todo mundo aprende do mesmo jeito. Poderia melhorar também nesse aspecto, pra mim. (Aluno 1, campus SGA, Informação Verbal). 
Você planejou, diversificou sua metodologia, você não concorda que isso é preciso sempre ser feito na prática do professor? (PAT, campus SGA, Informação Verbal).

Como se percebe, os entrevistados já visualizam uma série de ações que poderiam ser implementadas para favorecer a permanência do aluno no Curso Subsequente de Redes de Computares. Esta é uma questão que a instituição IFRN, em especial o campus SGA, precisa se preocupar e pensar de forma sistêmica para o fortalecimento dessas possíveis ações e deixar de ser algo pontual realizado por um ou outro servidor. A pesquisa constatou que a instituição já realiza algumas ações de fomento para a permanência do aluno, mas ainda não tem tido o efeito desejado.

\section{CONSIDERAÇÕES FINAIS}

Diante de todas essas questões pontuadas, podemos ver que se faz necessário que a escola cumpra o seu papel, no que diz respeito à permanência do aluno na escola, pois o ato de facilitar o processo do ensino aprendizado é de grande relevância para a promoção do desenvolvimento dos seus alunos.

O esforço no ensino aprendizado deve ser um movimento de mão dupla, ou seja, a finalidade de ensinar deve ir ao encontro da necessidade de se aprender. Dessa forma, professores e alunos poderão atingir seus objetivos.

Contudo, compreendemos que o aluno também tem sua responsabilidade nesse processo, principalmente nesse caso, uma vez que são alunos adultos, conscientes de suas responsabilidades; sendo assim, os professores, a escola como um todo, deve buscar estratégias para instigá-los para o esforço e para o comprometimento com seus estudos objetivando o sucesso de todos, pois temos a clareza de que o aluno é o alvo principal, dentro da instituição, e por isso deve-se ter uma preocupação maior, no sentido de fazê-lo sentir-se bem, no recinto educacional.

Outro sim, podemos ressaltar que todos os aspectos evidenciados pelos participantes da pesquisa que favorecem a permanência do aluno na escola, estão todos relacionados com aspectos internos à instituição; o que confirma os estudos de Rumberger (2004, apud DORE E SOARES, 2011). Como vimos, os fatores evidenciados nesta pesquisa, estão intrinsecamente ligados à perspectiva institucional, que se referem aos aspectos como: o perfil/desempenho do corpo discente, os recursos e estruturas físicas escolares, os processos e as práticas pedagógicas. Todos esses fatores foram citados pelos diferentes atores como importantes para favorecer a permanência do aluno.

E por fim, propomos como possível intervenção pedagógica para o enfrentamento desta problemática na realidade escolar, o desenvolvimento de um Plano de Ação Intersetorial de todos os profissionais que compõem a equipe multidisciplinar de fomento à permanência e sucesso do aluno do curso de Redes de Computadores, assim como a implementação de um sistema (software) ou até mesmo um módulo no SUAP (Sistema Unificado de Administração Pública) para que esta equipe possa criar um banco de dados, bem como monitorar toda a mobilidade estudantil para ter condições de, com base nesses dados, se pensar em ações e políticas de enfrentamento desta problemática na realidade escolar. 


\section{REFERÊNCIAS}

1. BRASIL. Lei no 11982, de 29 de dezembro de 2008. Institui a Rede Federal de Educação Profissional, Científica e Tecnológica, cria os Institutos Federais de Educação, Ciência e Tecnologia, e dá outras providências. Brasília/DF. Disponível em: portal.mec.gov.br. Acesso em: $20 / 08 / 14$

2. BRASIL. Lei no 9394 de 20 de dezembro de 1996. Estabelece as Diretrizes e Bases da Educação Nacional. Brasília/DF. Disponível em: portal.mec.gov.br. Acesso em: 20/08/14

3. BRASIL. Projeto de Lei $n=8.035 / 2010$. Dispõe do PLANO NACIONAL DE EDUCAÇÃO PARA 0 DECÊNIO 2011-2020. Disponível em: portal.mec.gov.br; Acesso em: 10/11/13.

4. BRASIL. Projeto de Lei $n$ ㅇ 8.035/2010. Dispõe do Plano Nacional de Educação para o Decênio 2011-2020. Disponível em: portal.mec.gov.br; Acesso: 10/11/13.

5. DORE, R.; LÜSCHER, A. Permanência e evasão na educação técnica de nível médio em Minas Gerais. Caderno de Pesquisa. vol.41 no.144, São Paulo Sept./Dec. 2011.Disponível em: www.scielo.br; Acesso: 10/01/14.

6. IBGE. Instituto Brasileiro de Geografia e Estatística. Censo Demográfico 2010. Educação e Deslocamento: resultados da amostra. Rio de janeiro, 2010. Disponível em: www.ibge.gov.br; Acesso em: 15/12/13.

7. IFRN. Projeto Político-Pedagógico do IFRN: uma construção coletiva, 2012. Disponível em: www.ifrn.edu.br; Acesso em: 15/05/13.

8. INEP. Censo da educação básica: 2012 - resumo técnico. - Brasília: Instituto Nacional de Estudos e Pesquisas Educacionais Anísio Teixeira, 2013.

9. RIBEIRO, C.S. Pedagogia da Repetência. Estud. av. vol.5 no.12 São Paulo May/Aug. 1991. Disponível em: www.scielo.br; Acesso em: 10/01/14.

10. SANTOS, M.J.C., POUCHAIN, J. F. Evasão Escolar no Ensino Médio Noturno: Um Estudo de caso na escola de Ensino Fundamental e Médio Prof. Jáder Moreira de Carvalho. Revista do Mestrado Profissional em Planejamento em Políticas Públicas. Ano: s/d. Disponível em: www.seer.uece.br; Acesso em: 20/05/13. 